\title{
INFLUÊNCIA DA TEMPERATURA SOBRE A BIOLOGIA REPRODUTIVA DO CAMARÃO ORNAMENTAL LYSMATA ANKERI, SOB CONDIÇÕES LABORATORIAIS.
}

\author{
Hirose, G.L. ${ }^{1, *} \&$ Santos, A.M.L. ${ }^{1}$ \\ ${ }^{1}$ Universidade Federal de Sergipe (UFS), Campus São Cristóvão, Laboratório de Carcinologia. \\ *Autor correspondente: gustavo_Ih@hotmail.com
}

Uma crescente demanda por organismos ornamentais marinhos vem fomentando uma indústria multibilionária em várias partes do mundo. Deste modo, nos últimos anos, um crescente esforço por parte dos pesquisadores vem sendo direcionado para o cultivo de crustáceos ornamentais. Atualmente, o sistema recirculante de água está bem estabelecido, permitindo a manutenção de indivíduos adultos com grande eficiência. Por outro lado, identificar as melhores condições para a manutenção dos progenitores ainda é fundamental para melhorar a qualidade da prole, diminuindo a mortalidade e o tempo de desenvolvimento durante a fase larval. O objetivo do presente trabalho foi avaliar os efeitos da temperatura sobre a biologia reprodutiva de Lysmata ankeri em condições laboratoriais. Indivíduos de $L$. ankeri foram coletados e transportados até o laboratório, e mantidos em pares reprodutivos, conectados a um sistema recirculante de água. Durante o período experimental, 10 pares reprodutivos foram mantidos durante três ciclos reprodutivos completos em cada tratamento térmico (23, 26 e $29^{\circ} \mathrm{C}$ ), sendo a biologia reprodutiva avaliada de acordo com a observação em dias do ciclo reprodutivo (período entre posturas), desenvolvimento embrionário, número e tamanho das larvas. Das três temperaturas avaliadas, apenas no tratamento de $29^{\circ} \mathrm{C}$ não foi obsevado nenhum evento de liberação larval. O Tempo

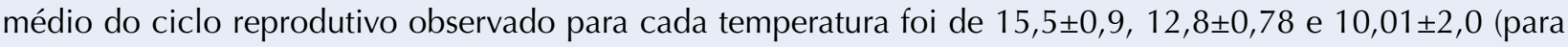
23,26 e $29^{\circ} \mathrm{C}$ respectivamente), demonstrando diferenças significativas (ANOVA, $p<0,05$ ) entre os tratamentos. Diferenças significativas também foram observadas com relação ao tempo de desenvolvimento embrionário (ANOVA, $\mathrm{p}<0,05)$. Na comparação entre o tamanho e número de larvas produzidas, diferenças significativas foram encontradas, de forma que as larvas obtidas na temperatura de $23^{\circ} \mathrm{C}$ foram mais numerosas, porém, de tamanhos menores, quando comparadas as larvas obtidas em $26^{\circ} \mathrm{C}$ (test $t, \mathrm{p}<0,05$ ). A temperatura demonstrou exercer uma grande influência sobre a reprodução de $L$. ankeri, influenciando tanto o ciclo reprodutivo quanto o número e tamanho das larvas obtidas. Larvas produzidas em $26^{\circ} \mathrm{C}$, apesar de menos numerosas, tiveram um tempo de desenvolvimento menor e tamanho maior sendo, provavelmente, mais indicada ao cultivo, devido à possibilidade de consumirem alimentos maiores, melhorando sua condição nutricional e diminuindo o tempo de cultivo.

Palavras-chave: camarão bailarino, ciclo reprodutivo, reprodução, hermafrodita, cultivo. 